\title{
VIOLÊNCIA CONTRA IDOSO: UM VELHO ESTIGMA
}

\author{
Cristiane Zamboni ${ }^{1}$, Sandra Maria Cardoso de Mello ${ }^{2}$, Rosane Fontana ${ }^{3}$, Francisco Carlos Pinto Rodrigues ${ }^{4}$
}

RESUMO: Estudo descritivo de abordagem qualitativa, que objetivou investigar as situações de violência contra idosos residentes na área de abrangência de uma Unidade Básica de Saúde da Estratégia Saúde da Família na região noroeste do Rio Grande do Sul. Os dados foram coletados no primeiro semestre de 2010 por meio de entrevista, usando questionário e o instrumento Avaliação de Violência e Maus Tratos Contra a Pessoa Idosa. Os resultados quantitativos apontaram a ocorrência de violência do tipo verbal, e a análise de conteúdo evidenciou duas categorias: Autonomia/independência e maus tratos; Limitações e maus tratos. Observou-se que os maus tratos estão relacionados à falta de autonomia e independência devido à limitada capacidade física e cognitiva frente às situações do cotidiano, gerando a necessidade de um cuidador. A Enfermagem deve auxiliar a sociedade a compreender o processo de envelhecimento, identificar a ocorrência de possíveis situações de violência e contribuir para sua prevenção.

PALAVRAS-CHAVE: Violência; Idoso; Autonomia pessoal; Enfermagem.

\section{VIOLENCE AGAINST THE ELDERLY: AN OLD STIGMA}

ABSTRACT: This descriptive study with a qualitative approach aimed to investigate the situations of violence against elderly residents of an area served by a Basic Health Unit of the Family Health Strategy in the North-East region of Rio Grande do Sul, Brazil. The data were collected in the first semester of 2010 through interviews, using the Evaluation of Violence and ill-treatment against the Elderly tool. The quantitative results indicated the occurrence of violence of a verbal nature, and content analysis provided two categories of evidence: Autonomy/independence and ill-treatment and Limitations and Ill-treatment. It was observed that ill-treatment is related to the lack of autonomy and independence due to limited physical and cognitive abilities in daily routines, leading to the need for a carer. Nursing must help society to understand the process of aging, to identify possible situations of violence, and contribute to its prevention.

KEYWORDS: Violence; Elderly; Personal autonomy; Nursing.

\section{VIOLENCIA CONTRA EL ANCIANO: UN VIEJO ESTIGMA}

RESUMEN: Estudio descriptivo de abordaje cualitativo, que tuvo el objetivo de investigar las situaciones de violencia contra ancianos que viven en área de abrangencia de una Unidad Básica de Salud de la Estrategia Salud de la Familia en la región noroeste de Rio Grande do Sul. Los datos fueron recogidos en el primer semestre de 2010 por medio de entrevista, usando cuestionario y el instrumento Evaluación de Violencia y Malos Tratos Contra la Persona Mayor. Los resultados cuantitativos apuntaron la ocurrencia de violencia del tipo verbal, y el análisis de contenido evidenció dos categorías: Autonomía/independencia y malos tratos; Limitaciones y malos tratos. Se ha observado que los malos tratos están relacionados a la falta de autonomía e independencia en razón de la limitada capacidad física y cognitiva delante de las situaciones del cotidiano, generando la necesidad de un cuidador. La enfermería debe auxiliar la sociedad a comprender el proceso de envejecimiento, identificar la ocurrencia de posibles situaciones de violencia y contribuir para su prevención. PALABRAS-CLAVE: Violencia; Anciano; Autonomía personal; Enfermería

${ }^{1}$ Acadêmica de Enfermagem da Universidade Regional Integrada do Alto Uruguai e das Missões - URI.

${ }^{2}$ Enfermeira. Mestre em Saúde e Gestão do Trabalho. Professora do Curso de Graduação em Enfermagem da URI. Membro do Grupo de Estudos e Pesquisas em Enfermagem Saúde e Educação - GEPESE.

${ }^{3}$ Professora. Doutoranda em Enfermagem pelo Programa de Pós-Graduação em Enfermagem da Escola de Enfermagem da Universidade Federal do Rio Grande do Sul. Professora do Cursos de Graduação e do Programa de Pós-Graduação da URI. Membro do GEPESE.

${ }^{4}$ Enfermeiro. Mestre em Enfermagem. Professor do Curso de Graduação e do Programa de Pós-Graduação em Enfermagem da URI.

Autor Correspondente:

Sandra Maria de Mello Cardoso

Universidade Regional Integrada do Alto Uruguai e das Missões

Av. Getúlio Vargas , 1426 - 98802-000 - Santo Ângelo-RS-Brasil

E-mail: scardoso@urisan.tche.br
Recebido: 12/07/2011

Aprovado: 07/10/2011

Cogitare Enferm. 2011 Out/Dez; 16(4):634-9 


\section{INTRODUÇÃO}

A transição demográfica está ocorrendo em todo o mundo e o envelhecimento faz parte da realidade da maioria das sociedades. Atualmente, o Brasil passa por uma grande mudança no perfil demográfico, estimandose que existam 17,6 milhões de idosos, cerca de $8 \%$ da população brasileira e, para os próximos 20 anos, a expectativa de pessoas acima de 60 anos é de 13\% da população. Assim, com o crescimento populacional de idosos, cresce também a necessidade de uma abordagem coletiva de saúde, visando diminuir a exclusão da assistência. Configura-se, com isso, um desafio para os profissionais de saúde, o que engloba os da Enfermagem, e para a sociedade em geral, procurando maneiras de melhorar a qualidade de vida dos idosos ${ }^{(1)}$.

A política aprovada no Conselho Nacional de Saúde, em 31/05/2006, pela Portaria n. 2.528/06, tem como propósito a saúde da pessoa idosa e, trabalha com dois grandes eixos: os idosos frágeis e os idosos independentes. $\mathrm{O}$ dispositivo apresenta como paradigma a capacidade funcional desta população ${ }^{(1)} \mathrm{e}$, a respeito deste aspecto, estudos revelam que a incapacidade funcional é ascendente após os 60 anos $^{(2)}$.

Sabendo-se que o avanço da idade impõe certas limitações, muitas vezes, torna-se necessária a presença de um cuidador, que pode ser um familiar ou não, com a finalidade de prestar auxílio e acompanhar o idoso no desempenho de suas atividades diárias, que englobam desde a higiene pessoal até a medicação, com o propósito de melhorar a qualidade de vida dessas pessoas ${ }^{(1)}$.

Nessa perspectiva, o cuidador pode ter uma sobrecarga aumentada de atividades que, com o decorrer do tempo, pode trazer à tona sentimentos e ações negativas para com o idoso, tais como o estresse, a irritação e impaciência, dentre outros, o que culmina em conflitos. Este fato é observado, geralmente, no momento em que se opõem formas diferentes de compreensão do cotidiano, ocorrendo um choque de culturas, principalmente por se tratar de gerações diferentes $^{(3)}$. Assim, emergem situações conflituosas entre a família, o idoso, os cuidadores, o provedor e o gestor de saúde, desencadeando processos decisórios difíceis ${ }^{(4)}$, além de contribuir para a configuração de cenários que podem levar à ocorrência de violência.

A violência contra pessoas idosas é definida como "o ato (único ou repetido) ou omissão que lhe cause dano físico ou aflição e que se produz em qualquer relação na qual exista expectativa de confiança"(1:43).

Ela pode se manifestar de forma estrutural, quando decorre da desigualdade social; de forma interpessoal, que se refere à relações cotidianas; e de forma institucional, que se reflete na gestão das políticas sociais pelas instituições de assistência ${ }^{(1)}$, com possibilidades de ocorrer abusos físicos, psicológicos, sexuais, abandono, negligência, abusos financeiros e autonegligência. Frequentemente, uma pessoa idosa sofre ao mesmo tempo vários tipos de maus tratos ${ }^{(5)}$.

Outro tipo de violência é o abandono, que pode ser causado pela fragilidade e dependência que acomete o idoso, afastando-os das relações familiares e sociais. Em 1980, um estudo constatou que as violências que mais atingiram esse grupo de pessoas foram os acidentes de trânsito e transporte, os homicídios e as quedas ${ }^{(6)}$. Hoje, a violência psicológica e física contra mulheres, crianças, trabalhadores e idosos, objeto deste estudo, tem sido denunciada constantemente pela mídia, tornando-se um problema de saúde pública.

Apesar de sua divulgação, há elementos que dificultam a denúncia de maus tratos por parte dos idosos, tais como o medo e a vergonha. Outro dado importante está no fato de que quanto mais idosa e dependente for a pessoa, maior é o risco de ser vítima de violência. Por isso, os profissionais de Enfermagem, e de saúde de modo geral, têm importante papel na interrupção e/ou interferência na violência, a partir de seu alerta para a observação de sinais e sintomas que possam evidenciar essas situações. Para tanto, o Ministério da Saúde, em 2006, disponibilizou um instrumento desenvolvido e validado em Porto Rico, e que possibilita identificar esses sinais. Para todo caso suspeito ou confirmado de violência contra a pessoa idosa, o profissional pode notificar a ocorrência por meio da "Ficha de Notificação/Investigação Individual - Violência Doméstica, Sexual e/ou Outras Violências"(1). Neste caso, o idoso deve ser encaminhado para os órgãos e instituições competentes, tais como as Delegacias de Polícias, os Conselhos Municipais dos Direitos das Pessoas Idosas, o Ministério Público, entre outros.

Percebe-se a existência de muitos aspectos legais e éticos envolvidos nessa questão. $\mathrm{O}$ idoso, quando vítima de algum tipo de violência e quando cognitivamente competente, tem o direito de determinar o curso da intervenção, optando até mesmo por nada fazer. Aos profissionais da saúde cabe avaliar cada caso em particular, bem como proporcionar suporte, orientação, notificação e encaminhamento adequado ${ }^{(1)}$.

Isto posto, o estudo teve como objetivo investigar as possíveis situações de violência contra a pessoa idosa, em uma área da Estratégia Saúde da Família de um município situado na região noroeste do Rio Grande do Sul.

\section{METODOLOGIA}

Trata-se de um estudo exploratório e descritivo, de abordagem qualitativa $^{(7)}$, do qual participaram dez idosos, 
de ambos os sexos, residentes na área de abrangência de uma Unidade Básica de Saúde da Estratégia Saúde da Família (ESF) de um município situado na região Noroeste do Rio Grande do Sul. Os participantes foram escolhidos por meio de sorteio, desde que obedecessem aos critérios de inclusão: ter idade acima de 60 anos, estar com suas capacidades mentais preservadas, ser residente em uma área adscrita da ESF e formalizar a participação na pesquisa.

A coleta de dados ocorreu em uma área da ESF, escolhida por meio de sorteio, e feita por meio de entrevista embasada no instrumento "Avaliação de Violência e Maus Tratos Contra a Pessoa Idosa"(1); que avalia possíveis situações de violência e que contém questões que versam sobre a presença e ocorrência de pessoas, cuidadoras ou não, que gritam, fazem uso inadequado do dinheiro do idoso, roubam ou maltratam fisicamente e/ou psicologicamente o idoso. Além disso, foi utilizado um questionário com perguntas abertas para obter respostas livres sobre informações mais variadas e complexas ${ }^{(7)}$, com questões que versaram sobre quem administra o dinheiro, o remédio, com quem mora o idoso e se necessita de alguém para algum tipo de ajuda.

Os instrumentos de coleta de dados foram aplicados no primeiro semestre de 2010, sendo a entrevista realizada no domicílio do idoso, em local reservado, longe de familiar ou cuidador, para que ele se sentisse mais à vontade para responder. Para a análise dos dados do questionário optou-se pelo método de análise do conteúdo das falas ${ }^{(8)}$. Os dados obtidos foram processados mediante análise estatística descritiva e apresentados em forma de tabela.

O estudo teve aprovação do Comitê de Ética em Pesquisa da Universidade Regional Integrada do Alto Uruguai e das Missões (URI), campus de Santo Ângelo, sob protocolo n. 120-4/PPH/09. De acordo com a regulamentação 196/96 do Conselho Nacional de Saúde, os sujeitos e familiares foram informados dos objetivos do estudo, bem como do direito a participar ou não da pesquisa, e da livre decisão de desistir se assim o desejasse, não resultando de sua participação ou recusa, nenhum risco à sua condição de usuário ${ }^{(9)}$. Para preservar a identidade dos entrevistados foi usada a designação caso 1, caso 2 e assim, sucessivamente. Foi apresentado aos sujeitos, antes do início da pesquisa, um Termo Consentimento Livre e Esclarecido, e ao gestor Municipal de Saúde foi encaminhado um ofício solicitando autorização para a realização do estudo. Os dados foram coletados somente após aprovação pelo Comitê de Ética em Pesquisa ao qual o estudo foi submetido, e autorização do gestor Municipal de Saúde.

\section{RESULTADOS}

Os dados relativos ao instrumento "Avaliação de Violência e Maus Tratos Contra a Pessoa Idosa"(1) foram analisados por meio da estatística descritiva, mediante distribuição da frequência, e demonstrados na tabela 1. Ressalta-se que o estudo não teve a intenção de associar variáveis.

Tabela 1- Ocorrência de maus tratos e violência. Rio Grande do Sul, 2010

\begin{tabular}{|c|c|c|c|c|c|c|}
\hline & \multicolumn{2}{|c|}{ NÃO } & \multicolumn{2}{|c|}{ SIM } & \multicolumn{2}{|c|}{$\begin{array}{l}\text { Frequência: } 1 \text { vez } \\
\text { ao mês ou menos }\end{array}$} \\
\hline & $\mathrm{n}$ & $\%$ & $\mathrm{n}$ & $\%$ & $\mathrm{n}$ & $\%$ \\
\hline $\begin{array}{l}\text { No último ano alguma das pessoas que o rodeiam tem gritado com } \\
\text { o senhor sem razão. }\end{array}$ & 8 & 80 & 2 & 20 & 2 & 20 \\
\hline $\begin{array}{l}\text { No último ano, algumas das pessoas que o rodeiam o tem chamado } \\
\text { por algum nome ou apelido que o senhor não goste. }\end{array}$ & 10 & 100 & - & - & - & - \\
\hline $\begin{array}{l}\text { No último ano alguma das pessoas que o rodeiam tem usado ou } \\
\text { manejado seu dinheiro sem seguir suas instruções. }\end{array}$ & 10 & 100 & - & - & - & - \\
\hline $\begin{array}{l}\text { No último ano, alguma das pessoas que o rodeiam o tem ameaçado } \\
\text { por não fazer o que eles querem que o senhor faça. }\end{array}$ & 10 & 100 & - & - & - & - \\
\hline $\begin{array}{l}\text { No último ano, alguma das pessoas que o rodeiam o tem golpeado, } \\
\text { batido ou esbofeteado. }\end{array}$ & 10 & 100 & - & - & - & - \\
\hline $\begin{array}{l}\text { No último ano, alguma das pessoas que o rodeiam o tem sacudido } \\
\text { ou segurado de forma intimidadora ou ameaçadora. }\end{array}$ & 10 & 100 & - & - & - & - \\
\hline $\begin{array}{l}\text { No último ano, alguma das pessoas que o rodeiam tem roubado } \\
\text { seu dinheiro ou algum de seus pertences. }\end{array}$ & 9 & 9 & 1 & 10 & 1 & 10 \\
\hline
\end{tabular}

Cogitare Enferm. 2011 Out/Dez; 16(4):634-9 
Embora $100 \%$ dos sujeitos afirmassem não ter passado, no último ano, por situações constrangedoras na forma de apelidos pejorativos, demonstrando o sentido de respeito mantido no grupo social que estão inseridos, dois referiram que foram alvo de agressão verbal, manifestadas por alterações de voz uma vez ao menos no mês. Todos relataram que nunca sofreram agressões físicas ou foram sacudidos ou coagidos fisicamente, no mesmo período. Da mesma forma, nenhum deles apontou problemas referentes a entregar seu dinheiro a terceiros, mantendo sua autonomia e poder de escolha para com os seus bens de consumo e controle de finanças.

Apenas um sujeito relatou que, no último ano, foi alvo de furto em sua residência, pois possui déficit em suas funções físicas e cognitivas, além de morar sozinho, se constitui alvo fácil de indivíduos desonestos.

A análise do conteúdo das falas do questionário permitiram o encontro de duas categorias: Autonomia/independência e maus tratos; e Limitações e maus tratos.

A categoria Autonomia/independência e maus tratos pode ser observada nas falas a seguir:

[...] eu faço minhas coisas sozinha e saio. Não fico em casa; ponho as panela no fogo, encaminho o almoço e só volto depois, prá terminar. (Caso 1)

Vou no posto sozinha, na doutora, pego minhas receitas aqui. Não vivo sozinha. Faço tudo que quero, na hora que quero. (Caso 5)

Me trazem remédio [filhos], minha aposentadoria quando dou cartão pra eles, pagam minhas contas, trazem o troco[...]. Tenho meu dinheirinho. (Caso 5)

Ele [neto] recebe o dinheiro no banco e me devolve o cartão e o dinheiro certinho, e dai eu mando ele pagar as contas que tenho. Faço as coisa como quero. Ele sempre obedeceu. (Caso 4)

Eu mesmo vou no banco, cuido meu dinheiro, minhas contas no mercado, sozinho aqui em casa. (Caso 2)

Não se metem. Eles [filhos] dizem que a mãe sempre faz o que ela quer. (Caso 1).

A categoria Limitações e maus-tratos foi identificada a partir da análise do conteúdo das falas, sendo representadas nas falas que seguem:
Por causa das vistas, eu mando o piá [neto] fazer coisas pra mim. Só vivo no meu pátio. E o piá tenta se 'retossá' comigo, às vezes, sabe como é esses piá, nessa idade. (Caso 3)

Não saio de casa sozinha, nem na calçada sozinha, por causa dos meus problema nas vistas. (Caso 4)

Não vou pelo centro me perco de vereda. Só saio sozinha aqui por perto. (Caso 8)

Tenho esse lado repuxado do derrame e fiquei fraco. Sozinho não caminho, tem que ter alguém pra me ajudar, ficar do lado. (Caso 7)

De vez em quando, ela ergue a voz pra mim, mas éo jeito dela [filha cuidadora]. Ela trabalha muito e tem problema dos nervos. (Caso 10)

\section{DISCUSSÃO}

Nesse estudo, foi possível observar que, mesmo com frequência não significativa, o tipo de violência prevalente contra o idoso é a verbal. Esta é manifestada por meio de gritos, atribuindo-se a justificativa, para o ato, a incapacidade do idoso gerada pelas dificuldades inerentes a esta etapa do desenvolvimento humano e por doenças características do processo de envelhecimento. Um estudo de revisão sistemática apontou que abusos verbais contra idosos são frequentes em várias regiões do mundo ${ }^{(10)}$.

As doenças crônicas, passíveis de aparecer no decorrer do processo de envelhecimento, podem produzir sequelas e gerar algumas incapacidades. Essas situações podem provocar sentimentos de fragilidade no idoso, em seu convívio social, sendo capazes de acarretar algum tipo de violência. A dependência parcial que muitas vezes acomete um idoso gera a necessidade da supervisão de um cuidador, ou do auxílio esporádico de alguém, em algumas atividades. Essa necessidade pode evoluir com o tempo, ficando o idoso dependendo cada vez mais da figura do cuidador; podendo chegar à dependência total, o que na maior parte das vezes tem relação com as situações de maus tratos e violência.

O cuidador familiar, neste cenário, participa cada vez menos das atividades sociais e pessoais e pode se sobrecarregar nos seus afazeres, tornando-se suscetível ao estresse, um agravo que facilita os casos de violência. Dessa forma, podem surgir situações conflitantes no dia a dia, provocadas por impaciência ou desordens rela- 
cionais, sendo os idosos sujeitos a serem coagidos com gritos e atitudes de irritação, provocando situações de violência intrafamiliar, muitas vezes distante dos olhos da sociedade. Nesse caso, o idoso que depende de alguém, mesmo que somente para algumas das atividades diárias, fica vulnerável a enfrentar sinais de maus tratos como gritos, apelidos pejorativos entre outros.

A relação entre o cuidador e o idoso dependente é complexa, principalmente porque o conflito entre gerações tende a se revelar à medida que as limitações físicas e sociais do idoso crescem e, dependendo do perfil psicológico de ambos, podendo ser muito difícil essa relação ${ }^{(4)}$.

Outros estudos já apontaram abusos por parte do cuidador, tais como agressões e impaciência ${ }^{(4)}$, que podem terminar em palavras proferidas em alto som, provocando a baixa auto-estima do idoso, bem como retraimento social. O cuidador pode equivocadamente deduzir, no decorrer dos cuidados prestados, que o idoso não tem capacidade de tomar suas próprias decisões, deixando de atentar para a vontade e desejos legítimos deste ${ }^{(4)}$.

Sabe-se que após os 60 anos, aumenta o número de pessoas com algum tipo de incapacidade, e esse número triplica após os 80 anos. Esse fato permite considerar que a condição funcional do idoso pode ser um fator em potencial para gerar situações de dependência e vulnerabilidade nas suas atividades diárias, o que leva a um aumento na procura pelos serviços de saúde ${ }^{(1-2)}$.

Por sua vez, a ausência de doenças, ou o seu controle, incita o idoso a cuidar de si mesmo e recusar a ideia de dependência e subordinação aos demais, formando uma barreira que o afasta de possíveis atos de maus tratos e violência, já que o risco de tais situações diminui quando ele é capaz de preservar sua autonomia e a independência ${ }^{(11)}$.

Tomando-se como ponto de partida que a independência e a autonomia são agentes potenciais de defesa e autoafirmação do idoso no meio social, essas duas condições alimentam um sentimento de liberdade de escolhas, que dá a ele a dimensão de ser dono de sí e de seu tempo. É importante que o mesmo realize o máximo de atividades diárias, para manter uma melhor qualidade de vida, e que as mesmas sejam respeitadas pelos familiares, profissionais ou cuidadores.

O idoso, mesmo que possua alguma doença e necessite de ajuda para realizar tarefas práticas do dia a dia - como o deslocamento, o enfrentamento de filas, a quitação de suas contas, as tarefas burocráticas e as operações em equipamentos eletrônicos - mantém, por meio do respeito e de bons laços familiares e sociais, as rédeas da situação e com poder de escolha, mesmo que venha a delegar tais tarefas a terceiros. Manter essa capacidade valoriza sua vida social, pois o transforma em alguém potencialmente capaz de interagir de igual para igual com os outros, impedindo a noção de inferioridade diante das pessoas. A realização das atividades básicas e instrumentais da vida diária é fundamental para indicar a independência dos idosos, o que foi percebido nos depoimentos apresentados durante o estudo e, que demonstram a satisfação não só de serem respeitados, mas, também de serem, efetivamente, seres autônomos, plenos da capacidade funcional. Em outras palavras, eles se tornam úteis e capazes de realizar tarefas do dia a dia, contrapondose ao paradigma de serem pessoas debilitadas ou sem utilidade para a sociedade.

Muitas vezes, é a sociedade que atribui ao idoso o papel de incapaz ou dependente, contribuindo para construir uma imagem negativa acerca do envelhecimento. Geralmente, essa imagem está associada à decadência, perda dos controles físicos e emocionais. Sendo assim, acredita-se que é fundamental refletir sobre as possibilidades e situações que geram a dependência do idoso por um cuidador no auxilio ou execução de ações que envolvem o cuidado sobre seu corpo, de modo a não haver distorções naquilo que ele tem de mais privado, a sua própria existência, uma vez que tende a perder a liberdade de decisão sobre o seu corpo, sobre sua vida ${ }^{(12)}$. Havendo condições psicofisiológicas, deve-se empenhar esforços para que idoso sinta-se autônomo, de modo a oportunizar-lhe o fortalecimento de sua dignidade e cidadania.

É possível perceber que quando a capacidade funcional do idoso não está prejudicada pelo processo de envelhecimento, ele é capaz de interagir com os outros de forma igualitária. E, seu poder de desígnio sobre sua vida é proporcional à sua adaptação aos limites impostos por problemas cotidianos, diminuindo, assim, as possibilidades de serem alvos de maus tratos.

Atualmente, já se observam algumas atitudes da sociedade para a diminuição da violência contra da mulher e contra a criança, mas ainda há negligência quanto à violência contra o idoso, embora mudanças de comportamento possam ser ressaltadas, em algumas comunidades. A violência ainda é mascarada, invisível. É preciso levar a discussão deste tema em diferentes segmentos da sociedade, tais como escolas, igrejas, famílias e reuniões políticas, incluindo os próprios idosos ${ }^{(13)}$.

É necessário atenção da Enfermagem para os sinais de maus tratos e as várias formas de violência, que podem ser sutis ou não e, então, discutir acerca desse 
problema. Para tanto, urge que esses profissionais de saúde, principalmente os que trabalham nas unidades da ESF e Unidades Básicas de Saúde, estejam preparados para distinguir as múltiplas formas em que a violência se evidencia e notificar os órgãos competentes, a fim de tirar este evento da invisibilidade, contribuindo para a humanização das relações.

\section{CONSIDERAÇÕES FINAIS}

A delimitação do tema teve como motivação a taxa crescente do envelhecimento da população, tendo em vista que, para a população em geral, a velhice é tratada muitas vezes como algo distante e alheio, sem perceber que não se pode manter o vigor e a independência da juventude para sempre.

A Enfermagem tem um papel importante nesse cenário, principalmente os que atuam nas ESF, que necessitam ser capacitados para estar atentos para perceber os sinais de maus tratos e violência que acometem aos idosos, a fim tomar as providências necessárias e encaminhamentos aos órgãos competentes.

Para que isso aconteça, é fundamental que tenham conhecimento acerca do processo de envelhecimento e das limitações que a idade pode impor, e assim esclarecer a população e os idosos sobre as estratégias para manter a autonomia e o respeito, visando a redução de situações de violência e maus tratos que, na maioria das vezes, acontece dentro das famílias e instituições.

Sugere-se, especificamente para os profissionais da Enfermagem, que se vinculem às ações de Saúde do Idoso e investiguem situações de violência nas suas áreas de atuação, buscando a prevenção de agravos e promoção da saúde destas pessoas que, em decorrência de fragilidades biológicas e mentais inerentes à idade, as impedem de reagir e se tornam alvos fáceis de indivíduos que desconsideram a ética e a solidariedade humana.

Sugerem-se outros estudos que permitam compreender as fragilidades do cuidador de idosos e os significados da relação entre os sujeitos para ampliar as concepções sociais deste fenômeno.

\section{REFERÊNCIAS}

1. Ministério da saúde (BR). Cadernos de Atenção Básica. Envelhecimento e saúde da pessoa idosa. Brasília; 2006.

2. Terra NL, Silva R, Schimdt OF. Tópicos em geriatria II. Porto Alegre (RS): Edipucrs; 2007.
3. Silva MJ, Oliveira TM, Joventino ES, Moraes GLA. A violência na vida cotidiana do idoso: um olhar de quem a vivencia. REE. [Internet] 2008;10(1):124-36 [acesso em 20 out 2010]. Disponível: http://www.fen. ufg.br/revista/v10/n1/v10n1a11.htm

4. Floriani CA, Schramm FR. Atendimento domiciliar ao idoso: problema ou solução? Cad Saude Publica. 2004;20(4):986-94.

5. Souza JAV, Freitas MC, Queiroz TA. Violência contra os idosos: uma análise documental. Rev Bras Enferm. 2007;60(3):268-72.

6. Lenardt MH, Hautschwillig M, Silva SC, Shimbo AY. O idoso institucionalizado e a cultura de cuidados profissionais. Cogitare Enferm. 2001;6(1):90-6.

7. Gil AC. Como elaborar projetos de pesquisa. $2^{\mathrm{a}}$ ed. São Paulo: Atlas; 1989.

8. Minayo CS, Gomes SFDR. Pesquisa Social: teoria, método e criatividade. $25^{\mathrm{a}}$ ed. Petrópolis (RJ): Vozes; 2007.

9. Ministério da Saúde (BR). Conselho Nacional de Saúde. Diretrizes e normas regulamentadoras de pesquisa envolvendo seres humanos. Resolução $n$. 196, de 10 de outubro de 1996. Brasília; 1996.

10. Espíndola CR, Blay SL. Prevalência de maus-tratos na terceira idade: revisão sistemática. Rev Saude Publica. 2007;41(2):301-6.

11. Minayo MCS. Violência contra idoso: relevância para um velho problema. Cad Saude Pública. 2003;19(3):783-91.

12. Tier CG, Fontana RT, Soares NV. Refletindo sobre idosos institucionalizados. Rev Bras Enferm. 2004;57(3):332-5.

13. Florêncio MVL, Ferreira Filha MO, Sá LD. A violência contra o idoso: dimensão ética e política de uma problemática em ascensão. REE. 2007; 9(3): 847-57 [acesso em 20 out 2010]. Disponível: http://www.fen. ufg.br/revista/v9/n3/v9n3a23.htm 